\title{
CUSTOM MADE ACRYLIC RESIN OCULAR PROSTHESIS USING A MODIFIED TECHNIQUE: A PRELIMINARY REPORT
}

\author{
Malaviya $\mathrm{N}^{1}$, Khanal $\mathrm{B}^{2}$, Yadav $\mathrm{A}^{1}$, Subhas $\mathrm{S}^{1}$
}

\begin{abstract}
The loss of one eye may be due to a congenital defect, pathology or trauma requiring the surgical removal of eyeball. This causes significant physical and emotional disturbance to the patient. Psychological distress can be reduced by timely replacement with an artificial eye. This preliminary report describes the fabrication of the custom made acrylic resin ocular prosthesis (CMAROP) with a modified technique where a stock eye shell has been used to fabricate a custom ocular impression tray. Try in was done on the same day. The CMAROP achieves intimate contact with the tissue bed and creates functional and esthetically pleasing results.
\end{abstract}

KEYWORDS: Enucleation, Ocular prosthesis, Acrylic eyes, Iris

1. Assistant Professor, Department of Prosthodontics and Maxillofacial Prosthesis UCMS College of Dental Surgery, Bhairahawa, Nepal

2. Post Graduate Resident, Department of Prosthodontics and Maxillofacial Prosthesis, UCMS College of Dental Surgery, Bhairahawa, Nepal

\author{
For Correspondence \\ Dr. Neha Malaviya \\ Assistant Professor, \\ Department of Prosthodontics and Maxillofacial Prosthesis, \\ UCMS College of Dental Surgery Bhairahawa, Nepal \\ E-mail: drnehamalaviya@gmail.com
}




\section{INTRODUCTION}

Throughout history, human eye has been mentioned by authors as most precious gift. It unveils entire outer world to our consciousness, gives life, expression and dignity to the face. The loss of an eye therefore has always been regarded as a great misfortune. Disfigurement resulting from loss of an eye can cause significant visual, psychological and social consequences.

Ocular defects may be associated with congenital deformities, tumors or acquired traumatic lesions. These defects may involve soft tissues within the orbital cavity and at times may also include the surrounding muscles and bones. The loss of an eye impairs the patient's visual function, yet also results in a noticeable deformity. Enucleation or evisceration causes constriction of the tissues around the ocular cavity or the eye socket. A temporary conformer to prevent tissue contraction will maintain proper contours.

An ocular prosthesis is a simulation of human anatomy using prosthetic materials. The primary purpose of the ocular prosthesis is to maintain the volume of eye socket and create an illusion of "perfectly normal healthy eye" and surrounding tissue. Ocular prosthesis is needed to raise spirits and ease the mind of the afflicted. ${ }^{2}$ The fabrication of the definitive ocular prosthesis should begin as soon as the socket is healed.

Here we describe modified simple technique of impression procedure, wax pattern try in and laboratory procedure for fabrication of an acrylic ocular prosthesis. The technique was performed in two patients - a young child and an adult.

\section{Clinical details of the patients}

Case 1: A 30 year old male patient (Figure 1a) came to Department of Prosthodontics and Maxillofacial Prosthesis, UCMS College of Dental Surgery, Bhairahawa with complaint of missing left eye. History revealed that he lost his eye consequent to some infection.

\section{Figure1a: Patient with left side ocular defect}

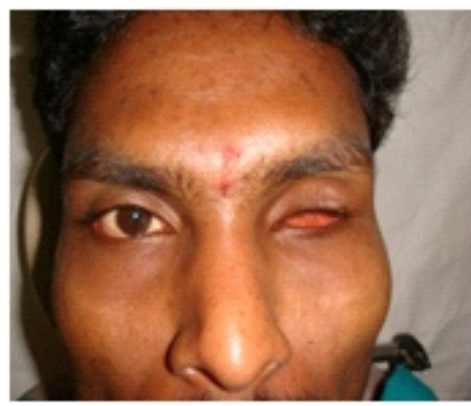

On examination, the surrounding bone was intact and provided a protective case for the globe contents. Most of the muscle attachments and fatty tissue that cushions the eye were preserved. The patient was not willing to undergo further surgery to place an implant, but was anxious to have an ocular prosthesis made as soon as possible.

Case 2: The second patient was a 3 year old girl (Figure 1b) who had undergone enucleation of her right eye for retinoblastoma.

\section{Figure 1b: Patient with right side ocular defect}

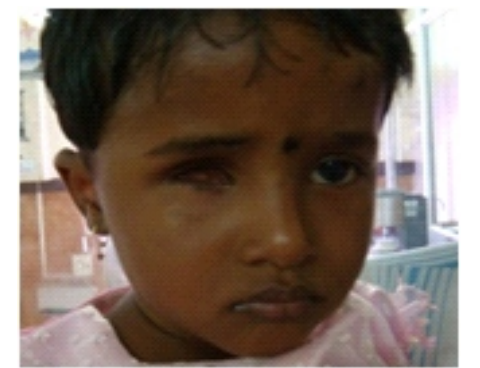

On examination, the eye socket was found to be asymptomatic and it was decided to fabricate an ocular prosthesis. The customized ocular prosthesis was fabricated to restore appearance and maintain the surgically created socket space.

\section{Technique of fabrication of prosthesis}

The treatment plan was explained to the patient / parents and informed consent was obtained. A simplified technique was used to fabricate eye prosthesis wherein a stock eye was used to construct the special tray to make the impression of the empty eye socket.

Step1: A glass stock eye which matched the colour and size of iris of the contralateral eye was selected followed by making alginate impression (Prime Dental Products Pvt. Ltd.) of the intaglio surface of the stock eye. (Figure 2a)

\section{Figure 2a: Alginate impression of stock eye}

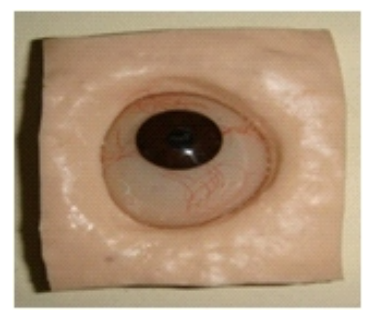

Step 2: Relief with two layers of modeling wax over the alginate impression was given which followed custom tray fabrication with clear self-cure acrylic resin (RR, Dentsply India Pvt. Ltd.) A plastic suction tube was attached through the custom tray for injecting impression material. (Figure. 2b and 2c) 


\section{CAse REPORT}

\section{Figure 2b: Wax relief over alginate impression}

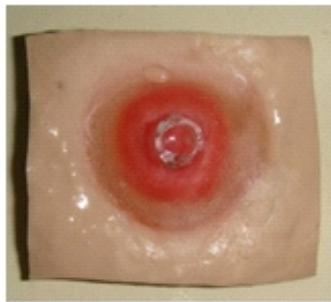

Figure 2c: Custom tray with suction tip attached

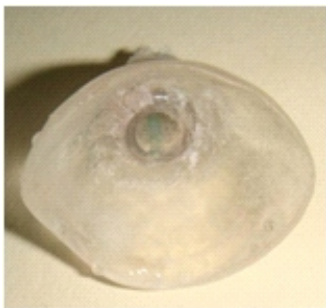

Step 3: Patient was placed in supine position and draped for impression procedure. The remnants of the patient's eyebrows and the area of skin covering the defect and the upper twothird of the face were lubricated with petroleum jelly.

Step 4: Impression of the eye socket was made by injecting addition silicone light body impression material (Aquasil LV, Dentsply India Pvt. Ltd) through the suction tip (Figure 2d). The patient was instructed to gaze straight ahead at a specified point as the material was getting set.

Figure 2d: Light body impression making of eye socket.

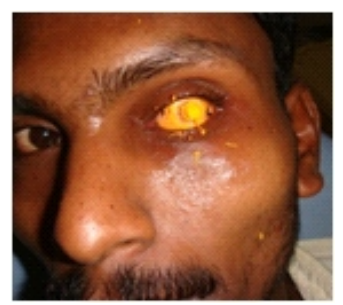

Step 5: Impression was poured in Type 3 Dental Stone (Kalstone, Kalabhai Karson Pvt. Ltd.) followed by wax pattern fabrication which was verified after try-in during which orientation of iris with respect to opposite eye ball was taken into consideration. (Figure $2 \mathrm{e}$ and $2 \mathrm{f}$ )

\section{Figure2e: Impression poured in type 3 Dental stone}

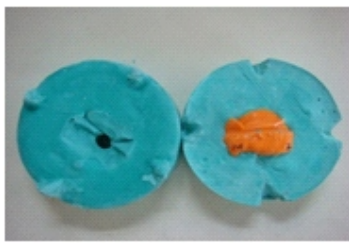

Figure 2f: Wax pattern try-in

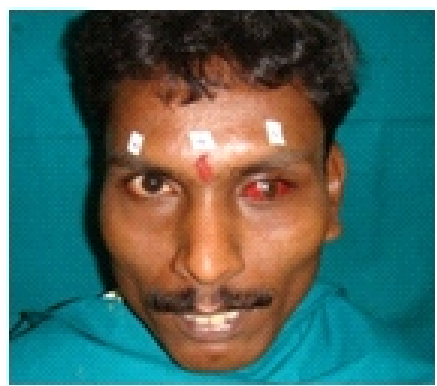

Step 6: Flasking of the wax pattern where an acrylic stent attached to stabilize the iris position during de-waxing was done (Figure 2g) which followed packing and curing with heat cure clear acrylic resin (Trevalon, Dentsply India Pvt. Ltd.) Nylon and Rayon fibers were added to characterize the eye prosthesis.

\section{Figure 2g: Acrylic stent for stabilizing iris}

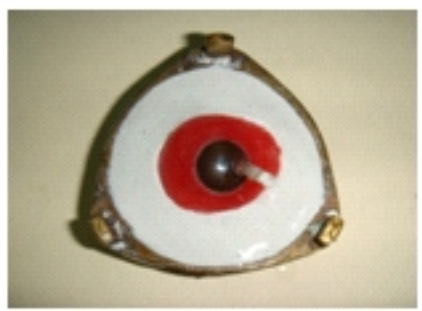

The prosthesis was finished and polished followed by insertion in the patient's eye socket.(Figure $3 a$ and $3 b$ )

Figure 3a: Final prosthesis (patient in Figure 1a)

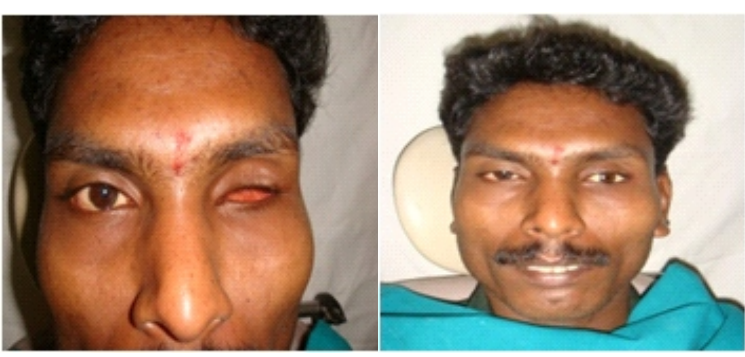

Figure 3b: Final prosthesis (patient in Figure 1b)

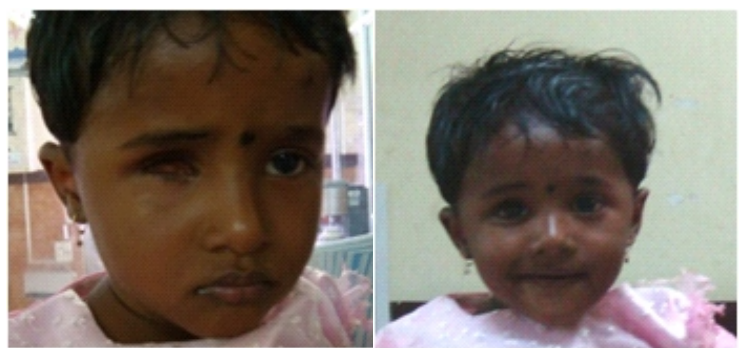




\section{Use and after care of the prosthesis}

Patients and or their attendants were given instructions on how to use and care the prosthesis. The method of insertion and removal of prosthesis and its care were demonstrated. They were instructed to raise the upper eyelid with opposite hand, insert the prosthesis and manipulate the lower lid over it.

The prosthesis was to be removed at night and kept in water or contact lens soaking solution. Cleaning was to be done with hand using a mild liquid surfactant such as baby shampoo in the morning before insertion into the socket. The patients were asked to return on day 1, 2 and 7 for follow-ups after the prosthetic insertion. There after a six month to one year follow up was done for prosthesis evaluation and adjustment.

\section{DISCUSSION}

Physical defects that compromise appearance or function which prevents an individual from leading a normal life, usually prompt the individual to seek treatment that will reinstate acceptable normalcy. The aim of rehabilitation procedure is to return the patient to the society with a normal appearance, comfort and reasonable mobility of the ocular prosthesis.

Prosthetic rehabilitation is enhanced if an implant can be placed in the orbit to provide an attachment for the rectus muscles. However the placement of an ocular implant is not always feasible. Patients in such situations can be treated with custom made ocular prosthesis that has been adapted to accommodate specific situations. Several techniques are available for this purpose.

The custom made ocular prosthesis conforms accurately to the socket since fabrication of the ocular prosthesis is based on the existing anatomy of the patient. It is therefore better adapted to the available space allowing movements of the eyeball and exact match of the iris position, to that of natural adjacent eye. ${ }^{3,4}$ The fabrication of a custom acrylic eye (CMAROP) provides more esthetic and precise results because an impression establishes the defect contours and the iris and the sclera are custom fabricated. ${ }^{4}$

The results we obtained have been shown in Figure $3 \mathrm{a}$ and $3 \mathrm{~b}$. The patients were satisfied with the match and fit of the prosthesis. In the technique we described, a stock eye shell was used to fabricate a custom ocular impression tray which conformed to the walls of the defect better. Try in was done in the same day. ${ }^{5}$ Critical fabrication step involves the impression of the socket. Try in is important to evaluate fit, determine the eye lid opening and overlying contours of the tissue $^{6,7}$ thus giving benefits of increased adaptation, movement of the eye ball. Even though the fabrication time and costs are more, comparing to the benefits it offers, it is a small pay off.

\section{CONCLUSION}

The major advantages of a custom ocular prosthesis are improved fit, mobility and esthetics. The fabrication of a custom acrylic eye provided better esthetic and precise results because defect contours were accurately established during impression. The iris and sclera were custom fabricated. In our technique a stock eye shell was used to fabricate a custom ocular impression tray which conformed to the walls of the defect better.

\section{REFERENCES}

1. Ivy RH. Manual of standard practice of plastic and maxillofacial surgery. Philadelphia and London: W B Saunders, 1942;13:34175 .

2. Sykes LM. Custom made ocular prostheses: A clinical report. $J$ Prosthet Dent 1996;75:1-3. http://dx.doi.org/10.1016/S0022-3913(96)90409-6

3. Ow RKK, Amrit S. Ocular prosthetics: use of a tissue conditioner material to modify a stock ocular prosthesis. J Prosthet Dent 1997;78:218-22.

http://dx.doi.org/10.1016/S0022-3913(97)70129-X

4. Supriya M, Ghadiali B. Prosthetic rehabilitation of a patient with an orbital defect using a simplified approach. J Indian Prosthodontic Soci 2008;8:116-8.

http://dx.doi.org/10.4103/0972-4052.43616

5. Welden RB, Niiranen JV. Ocular Prosthesis. J Prosthet Dent 1956;6:272-8.

http://dx.doi.org/10.1016/0022-3913(56)90120-2

6. Kathuria N. A modified technique and simplified laboratory procedure for Ocular Prosthesis Fabrication. Journal of Prosthodontic Research 2012;56:147-150.

http://dx.doi.org/10.1016/j.jpor.2011.07.002 PMid:22104621

7. Mathews MF, Smith AJ, Hudson R. The ocular impression: a review of the literature and presentation of an alternative technique. JProsthodont 2000;9:210-6.

http://dx.doi.org/10.1111/j.1532-849X.2000.00210.x

http://dx.doi.org/10.1053/jpro.2000.21157 PMid:11320473 